\section{Pulmonary extramedullary hematopoiesis involving the pulmonary artery}

\author{
Varun Monga, Margarida Silverman \\ Division of Hematology/Oncology and \\ Bone Marrow Transplantation, University \\ of lowa Hospitals and Clinics, lowa City, \\ IA, USA
}

\section{Abstract}

Extramedullary hematopoiesis (EMH) occurs as a complication of hematologic disorders such as myelofibrosis, sickle cell anemia and thalassemia. The extramedullary tissue usually involves liver, spleen and lymph nodes, less frequently the chest. We present a recent case of a man with myeloproliferative neoplasm who developed pulmonary hemorrhage secondary to EMH in the lung and pulmonary artery. Radiation therapy was considered the best approach, but it didn't work and the patient died a week after radiation therapy was completed. We also review herein the present literature.

\section{Introduction}

Extramedullary hematopoiesis (EMH) occurs as a complication of hematologic disorders such as myelofibrosis, sickle cell anemia, and thalassemia. The extramedullary tissue usually involves the liver, spleen and lymph nodes. Although it has been described as occurring at almost any organ/site in the body, it has been infrequently reported in the chest. When described in chest, it has been generally detected as paravertebral masses seen on chest $\mathrm{x}$-ray. ${ }^{1-6}$ It is important to make this diagnosis as EMH can be associated with intrathoracic cord compression, and rarely fatal hemothorax. ${ }^{5}$ It is amenable to therapy with both hydroxyurea and radiation.

\section{Case Report}

A 53-year-old Caucasian man presented with a year history of myelodysplastic syndrome/myeloproliferative neoplasm (MDS/MPN) and marrow fibrosis (negative JAK-2 V617F point mutation). He was seen with epistaxis and hemoptysis of two days duration. He had been on ruxolitinib for six months with improvement in appetite and decreased pain secondary to an enlarged spleen. He was being considered for allogeneic stem cell transplantation. Physical examination was significant for a fever of $101.3^{\circ} \mathrm{F}$, fine crackles at the right base and an enlarged spleen. Laboratory analyses showed a white blood cell count of $27,500 / \mathrm{mm}^{3}$, hemoglobin level of $7.8 \mathrm{~g} / \mathrm{dL}$, hematocrit of $27 \%$ and platelet count of $22,000 / \mathrm{mm}^{3}$. Peripheral blood smear review showed markedly increased monocytes many of which appeared atypical. Computed tomographic (CT) scan of the chest with contrast showed a right pulmonary artery filling defect which extended into the right middle lobe (Figure 1A). Enlarged subcarinal, aortopulmonary lymph nodes, splenomegaly and a right liver mass were also seen. Given his longterm smoking history, there was concern that a second malignancy might be present. A recent biopsy of the liver mass had EMH. The differential diagnoses of the right middle lobe and pulmonary artery mass included thromboembolic disease, primary lung malignancy, sarcoma, pneumonia or EMH. An endobronchial ultrasound guided aspiration of the subcarinal lymph node and right pulmonary artery mass showed findings consistent with EMH (Figure 1B). A bone marrow biopsy was performed which showed hypercellular bone marrow (>90\%) with decreased megakaryocytes, erythroid dyspoiesis and left shifted granulopoiesis with $5 \%$ blasts, a peripheral monocytosis, and moderate marrow fibrosis consistent with chronic myelomonocytic leukemia-2. He received 14 Gy of the planned 20 Gy external beam radiation therapy in 7 fractions using AP/PA approach with $10 x$ energy to the right lung mass as outpatient. Ruxolitinib was stopped due to thrombocytopenia (platelet count of $48,000 / \mathrm{mm}^{3}$, PT $-15 \mathrm{sec}$ and INR 1.5). A week later he presented with a hematoma of his right thigh, severe anemia (hemoglobin $5.5 \mathrm{gm} / \mathrm{dL}$ ), elevated white blood cell count $\left(89,700 / \mathrm{mm}^{3}\right)$ with predominant monocytosis. He was started on hydroxyurea and received a single dose of decitabine for presumed acute leukemia. The patient suddenly became hypoxemic. Chest x-ray showed right sided pleural effusion. A diagnostic thoracentesis revealed bloody pleural fluid. Cytology of the pleural fluid showed hematopoietic cells similar to the ones noted in the pulmonary artery aspirate specimen. At that time his platelets were $76,000 / \mathrm{mm}^{3}$. The patient was deemed to be inoperable given the multiple comorbidities and he died a day later. Autopsy was not performed.

\section{Discussion}

Extramedullary hematopoiesis is a compensatory hematopoietic tissue expansion usually involving the reticulo-endothelial system. EMH
Correspondence: Varun Monga, University of Iowa Hospitals and Clinics, C-32 GH, Iowa City, IA 52242, USA.

Tel.: +1.319.356.2075 - Fax: +1.319 .353 .8383$

E-mail: varun-monga@uiowa.edu

Key words: pulmonary, extramedullary, hematopoiesis, myeloproliferative neoplasms.

Contributions: the authors contributed equally.

Conflict of interest: the authors declare no potential conflict of interest.

Received for publication: 1 November 2014. Accepted for publication: 9 February 2015.

This work is licensed under a Creative Commons Attribution NonCommercial 3.0 License (CC BYNC 3.0).

(C) Copyright V. Monga and M. Silverman, 2015 Licensee PAGEPress, Italy

Hematology Reports 2015; 7:5714

doi:10.4081/hr.2015.5714

and myeloid metaplasia have been interchangeably used in the past and refer to the similar pathological process. ${ }^{7}$ Whether EMH represents differentiation of embryonic stem cells residing within the vessel wall or implantation of hematopoietic tissue escaping from the bone marrow remains uncertain.

Pulmonary EMH (PEMH) has been rarely reported. The majority of the pulmonary EMH masses are asymptomatic. However patients sometimes present with hemoptysis, ${ }^{8}$ acute or progressive dyspnea or chest pain. Patients can sometimes present with life threatening complications such as massive pleural effusion, hemothorax, ${ }^{9}$ chylothorax, ${ }^{10}$ or spinal cord compression (posterior mediastinal EMH). ${ }^{11}$ Differentiation between thromboembolic disease and extramedullary hematopoiesis in such cases can be very critical as the treatments strategies are different for each. Several other non-infectious pulmonary complications of MDS/MPN have been described in the literature. ${ }^{12}$ Hematopoietic tissue is known to be sensitive to low doses of radiation therapy. The role of radiation therapy in treating patients with EMH causing spinal cord compression has been well established. ${ }^{11,13}$ Radiation therapy to the lung has been successfully used to treat EMH involving the lung parenchyma. ${ }^{9,14,15}$ The median suggested dose of radiation is $1.25 \mathrm{~Gy}$. Combined modality treatment with radiation and surgery perhaps would be a better approach reserving surgery for only emergent management. Table 1 outlines the published cases of pulmonary EMH, the respective interventions utilized and the corresponding treatment outcomes. ${ }^{4,5,8-10,14-20}$ 
Table 1. Reported cases of patients with underlying myeloproliferative disease presenting with pulmonary involvement by extramedullary hematopoiesis, respective interventions and their outcomes. Diagnosis of pulmonary extramedullary hematopoiesis made ante mortem.

\begin{tabular}{|c|c|c|c|c|}
\hline Case & Underlying disease & Presentation & Treatment for EMH & Outcome \\
\hline Pinato et al. ${ }^{4}$ & Myelodysplasia & Progressive dyspnea & None & Unknown \\
\hline Chute et al..$^{5}$ & ickle cell trait/ $\beta$-thalassemia & Hypoxia & Thoracostomy & Died from hemothorax \\
\hline Ozbudak et al. ${ }^{8}$ & Myelofibrosis & Dyspnea and hemoptysis & Prednisone, hydroxyurea, busulfan & $\begin{array}{l}\text { Minimal improvement; died } \\
\text { of MI after } 2 \text { mths }\end{array}$ \\
\hline Kupferschmid et al. ${ }^{9}$ & Myelofibrosis & Dyspnea & Thoracotomy + radiation 1.4 Gy in 10 fractions & Died of pneumonia \\
\hline Ghosh et al. ${ }^{10}$ & None & Progressive dyspnea & $\begin{array}{c}\text { Thoracostomy with talc } \\
\text { pleurodesis + radiation } \\
2 \text { Gy in } 4 \text { fractions }\end{array}$ & Complete resolution \\
\hline Koch et al. ${ }^{14}$ & $\begin{array}{l}2 \text { cases: agnogenic } \\
\text { myeloid metaplasia }\end{array}$ & $\begin{array}{l}\text { Dyspnea, orthopnea, } \\
\text { edema weight gain }\end{array}$ & $\begin{array}{l}1 \text { Gy in } 1 \text { fraction of radiation; } \\
1.5 \text { Gy in } 10 \text { fractions }\end{array}$ & Complete resolution \\
\hline Weinschenker et al..$^{15}$ & Myelofibrosis & Dyspnea & Whole lung radiation $200 \mathrm{~Gy} / 4$ fractions & Complete resolution \\
\hline Rumi et al..$^{16}$ & Myelofibrosis & Progressive dyspnea & Hydroxyurea & Complete resolution after $3 \mathrm{mths}$ \\
\hline Ueno et al. ${ }^{17}$ & Myelofibrosis & Fever and fatigue & Steroids started day 90 & Died 10 days later \\
\hline Yusen et al..$^{18}$ & Myelofibrosis & $\begin{array}{l}\text { Dyspnea, cough, fevers } \\
\text { and night sweats }\end{array}$ & 2 days interferon and supportive care & Died due to respiratory failure \\
\hline Asakura et al. ${ }^{19}$ & $\begin{array}{l}\text { Myelofibrosis; agnogenic } \\
\text { myeloid metaplasia }\end{array}$ & $\begin{array}{l}\text { Dyspnea; dyspnea } \\
\text { and fatigue }\end{array}$ & Steroids and diuretics; unknown & Died 6 mths later; died 13 mths later \\
\hline Glew et al. ${ }^{20}$ & Myelofibrosis & Fevers & None & Died 5 months later \\
\hline
\end{tabular}

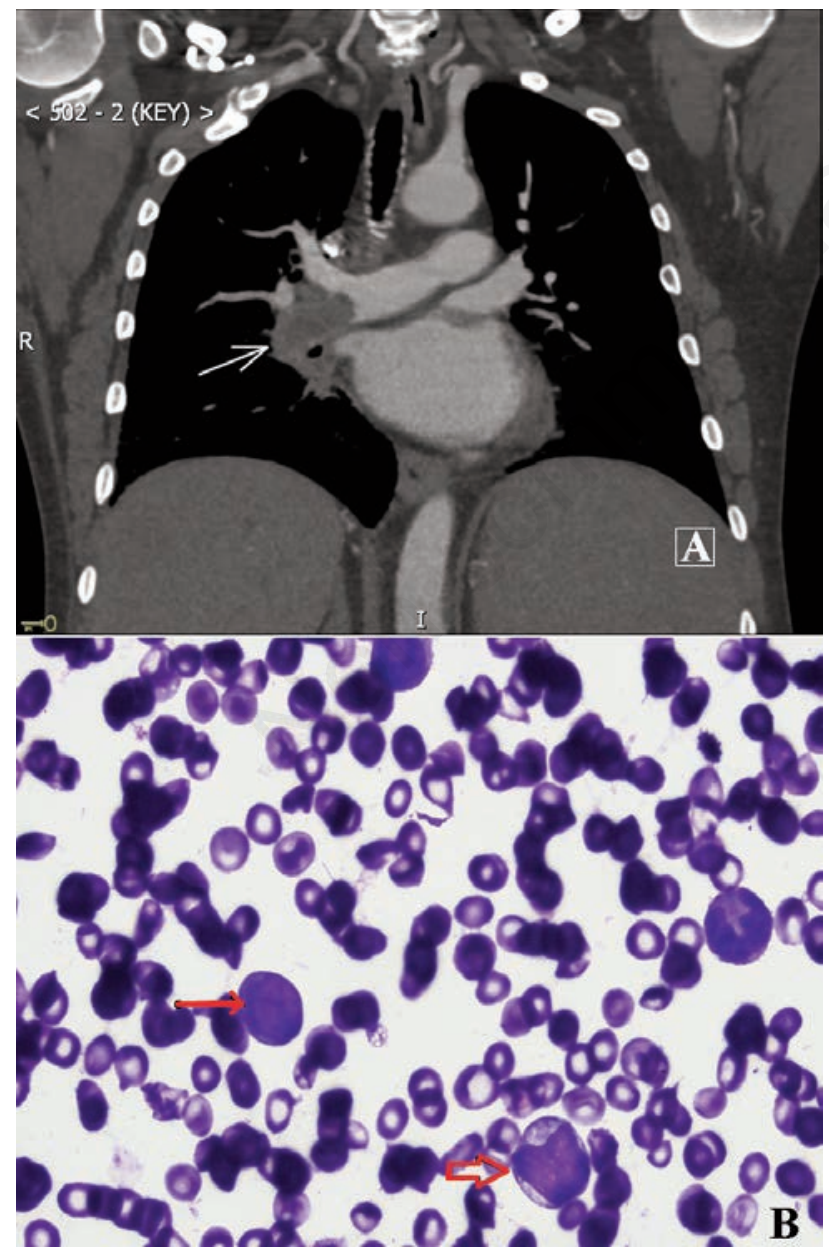

Figure 1. A) Coronal view of post contrast computed tomography imaging of the chest with arrow pointing towards the filling defect within the right pulmonary artery. B) High power view of Hematoxylin and Eosin stain of the endobronchial ultrasound guided aspirate of the right pulmonary artery thrombus showing extramedullary hematopoiesis with immature myeloid cells (box arrow) and focally increased areas of blasts (line arrow).
In our patient several factors could have contributed to the pulmonary hemorrhage including the underlying hematological condition leading to thrombocytopenia and coagulopathy. The transbronchial biopsy procedure could have caused the hemothorax as these hematopoietic masses are very likely to bleed upon intervention. However the 14 day time lag between the procedure and bleeding makes it less likely. Radiation therapy to the hematopoietic mass tissue in the lung could have potentially leaded to necrosis of the tissue thereby causing hemothorax. Review of the other pulmonary EMH case studies suggests that radiation therapy to the lung has led to the best outcomes.

\section{Conclusions}

In summary, we present a patient with myeloproliferative neoplasm who developed pulmonary hemorrhage secondary to EMH in the lung and pulmonary artery. Although rare, presentation of hemoptysis in a patient with underlying myeloproliferative neoplasm should prompt clinicians to consider EMH involving the pulmonary artery in the differential diagnoses. Early recognition of the diagnosis remains important. Radiation therapy to the lung mass (or the whole lung if pulmonary hypertension is diagnosed) can be considered as the best approach if patient is hemodynamically stable recognizing that it may not always work. 


\section{References}

1. Mandal PK, Dolai TK. Intrathoracic extramedullary hematopoiesis in E-beta thalassemia. Indian $\mathrm{J}$ Pathol Microbiol 2014;57:497-8.

2. Da Costa JL, Loh YS, Hanam E. Extramedullary hemopoiesis with multiple tumor-simulating mediastinal masses in hemoglobin E-thalassemia disease. Chest 1974;65:210-2.

3. Zhou B, Yan S, Zheng S. Intrathoracic extramedullary hematopoiesis mimicking intrathoracic tumors: a case report. Oncol Lett 2014;7:1984-6.

4. Pinato DJ, Tan W, Gately A. An unexpected cause of pulmonary cannonball lesion. J Thorac Oncol 2014;9:259.

5. Chute DJ, Fowler DR. Fatal hemothorax due to rupture of an intrathoracic extramedullary hematopoietic nodule. Am J Forensic Med Pathol 2004;25:74-7.

6. Santini M, Fiorelli A, Vicidomini G, et al. Intrathoracic extramedullary haematopoiesis manifested as a neoplastic lesion within anterior mediastinum. Ann Thorac Surg 2009;88:2001-4.

7. Tefferi A. Myelofibrosis with myeloid metaplasia. N Engl J Med 2000;342:125565.
8. Ozbudak IH, Shilo K, Hale S, et al. Alveolar airspace and pulmonary artery involvement by extramedullary hematopoiesis: a unique manifestation of myelofibrosis. Arch Pathol Lab Med 2008;132:99-103.

9. Kupferschmid JP, Shahian DM, Villanueva AG. Massive hemothorax associated with intrathoracic extramedullary hematopoiesis involving the pleura. Chest 1993; 103:974-5.

10. Ghosh AK, Pawade J, Standen GR, et al. Primary extramedullary hematopoiesis manifesting as massive bilateral chylothorax. Ann Thorac Surg 2005;80:1515-7.

11. Scott IC, Poynton CH. Polycythaemia rubra vera and myelofibrosis with spinal cord compression. J Clin Pathol 2008;61:681-3.

12. Lamour C, Bergeron A. Non-infectious pulmonary complications of myelodysplastic syndromes and chronic myeloproliferative disorders. Rev Mal Respir 2011;28:e18-27.

13. Papavasiliou C, Gouliamos A, Deligiorgi E, et al. Masses of myeloadipose tissue: radiological and clinical considerations. Int $\mathrm{J}$ Radiat Oncol Biol Phys 1990;19:985-93.

14. Koch CA, Li CY, Mesa RA, et al. Nonhepatosplenic extramedullary hematopoiesis: associated diseases, pathology, clinical course, and treatment. Mayo Clin Proc 2003;78:1223-33.

15. Weinschenker P, Kutner JM, Salvajoli JV, et al. Whole-pulmonary low-dose radiation therapy in agnogenic myeloid metaplasia with diffuse lung involvement. Am J Hematol 2002;69:277-80.

16. Rumi E, Passamonti F, Boveri E, et al. Dyspnea secondary to pulmonary hematopoiesis as presenting symptom of myelofibrosis with myeloid metaplasia. Am J Hematol 2006;81:124-7.

17. Ueno H, Yoneda R, Ogawa W, et al. Bilateral interstitial pneumonic shadows caused by perivascular fibrosis and extramedullary megakaryopoiesis of the lung in a case of advanced agnogenic myeloid metaplasia and myelofibrosis. Acta Haematol 2000;104:212-6.

18. Yusen RD, Kollef MH. Acute respiratory failure due to extramedullary hematopoiesis. Chest 1995;108:1170-2.

19. Asakura S, Colby TV. Agnogenic myeloid metaplasia with extramedullary hematopoiesis and fibrosis in the lung. Report of two cases. Chest 1994;105:18668.

20. Glew RH, Haese WH, McIntyre PA. Myeloid metaplasia with myelofibrosis. The clinical spectrum of extramedullary hematopoiesis and tumor formation. Johns Hopkins Med J 1973;132:253-70. 